\title{
Which ovarian reserve marker relates to embryo quality on day 3 and blastocyst; age, AFC, AMH?
}

\author{
Juliano Brum Scheffer ${ }^{1}$, Rafaela Friche de Carvalho ${ }^{1}$, Ana Paula de Souza Aguiar ${ }^{1}$, Iole Joana Moreira Machado ${ }^{1}$ \\ Juliana Baumgratz Franca ${ }^{1}$, Daniel Mendez Lozano², Renato Fanchin ${ }^{3}$ \\ ${ }^{1}$ IBRRA - Brazilian Institute of Assisted Reproduction, Belo Horizonte, Brazil \\ ${ }^{2}$ School of Medicine, Tecnologico de Monterrey and Center for Reproductive Medicine CREASIS, San Pedro \\ Monterrey, Mexico \\ ${ }^{3}$ Professeur des Universites - Praticien Hospitalier en Medecine de la Reproduction, France; Hopital Foch, France
}

\begin{abstract}
Objective: The aim of the present prospective study was to evaluate which ovarian reserve marker would be more reliable as the quality of the $A+B$ embryos (day 3 and blastocyst).

Methods: We ran a prospective study with 124 infertile women, aged 24-48 years, from 2017 to 2018. The patients were divided into 3 groups according to age and the subgroups were compared for $A M H, A F C$, number of $\mathrm{A}+\mathrm{B}$ embryos. New division of the 3 groups was performed based on the $A M H$, and the subgroups were compared for age, AFC and number of $A+B$ embryos. Finally, we divided the patients into 3 groups, based on the $A F C$, and we compared the subgroups for age, $\mathrm{AMH}$ and number of $\mathrm{A}+\mathrm{B}$ embryos. $P<0.05$ was considered statistically significant.

Results: When the 124 patients were divided according to age, we found a significant fall in an $A+B$ embryo quality (day3; blastocyst) after 35 years $(p<0.038 ; p<0.035)$, and more severely after 37 years $(p<0.032 ; p<0.027)$. When the 124 patients were divided according to $A M H$, there was a significant fall in $A+B$ embryo quality (day 3 ; blastocyst), with $A M H<1 \mathrm{ng} / \mathrm{ml}(p<0.023 ; p<0.021)$. When the 124 patients were divided according to AFC, there was a significant fall in $A+B$ embryo quality (day 3 ; blastocyst) with AFC $<7(p<0.025 ; p<0.023)$. These markers had significant associations with embryo quality $(p<0.005)$.
\end{abstract}

Conclusion: Age, AFC and AMH have significant associations with $A+B$ embryo quality on day 3 and blastocyst.

Keywords: $\mathrm{AMH}$, age, antral follicle count, ovarian reserve, embryo quality

\section{INTRODUCTION}

Fertility rates start to decrease in women older than 35 years of age, due to a decrease in the number of normal oocytes available. This process is a consequence of oocyte atresia and, although this normally happens to happen to all women, there is no certainty in predicting the rate of decay. This decay is age-related, where there is a decrease in ovarian quality, number of oocytes and markers of ovarian activity through a gradual increase in circulating $\mathrm{FSH}$, and a decrease in circulating anti-Müllerian hormone $(\mathrm{AMH})$, and antral follicle count (AFC).

The effects of female age on fertility was found in a classic report, where the percentage of women who did not use contraceptives remained childless, steadily after increasing according to their marriage age: $6 \%$ in the 20 to 24 age group; $9 \%$ in the 25 to 29 age group; $15 \%$ in $30-34$ years old; $30 \%$ in $35-39$ years old and $64 \%$ in $40-44$ year-olds (Vigier et al., 1984).
Success rates in assisted reproductive technologies in 2001 show that the percentages of clinical pregnancies (ultrasound-visible gestational sac) that did not result in a live birth were $14 \%$ for women under 35 years of age; $19 \%$ for those 35 to 37 years of age; $25 \%$ for those 38 to 40 years old and $40 \%$ for those over 40 years old (CDC, 2003).

Age-related decay in female fertility and increased risk of miscarriage are largely attributed to oocyte abnormalities. The meiotic spindle in the oocytes of elderly women regularly exhibits abnormalities in chromosomal alignment and microtubular matrix composition (di Clemente et al., 1992). Higher rates of single chromatid abnormalities in oocytes (Weenen et al., 2004), aneuploidy in preimplantation embryos (Durlinger et al., 2002) and ongoing pregnancies may be found in older women. The rate of aneuploidy is a major cause of increased miscarriage and decreased live birth rates in women of advanced reproductive age.

Ovarian reserve assessment has recently been the focus of many clinical studies (Guibourdenche et al., 2003; Rajpert-De Meyts et al., 1999; La Marca et al., 2005; de Vet et al., 2002; Fanchin et al., 2003). Thus, anti-Müllerian hormone $(\mathrm{AMH})$, also called Müller inhibitory substance, is a dimeric glycoprotein that belongs to the transforming growth factor-b (TGF-b) superfamily, such as activins and inhibins, being produced exclusively in the gonads. In females, AMH is synthesized by granular cells (GC) around the preantral and small antral follicles (Weenen et al., 2004; Durlinger et al., 2002). AMH is almost undetectable in serum at birth, and it can reach higher levels after puberty (Guibourdenche et al., 2003; Rajpert-De Meyts et al., 1999), although it then decreases with advancing age, where it becomes again undetectable at menopause ( $\mathrm{La}$ Marca et al., 2005). Although the physiological roles and mechanisms involved in AMH regulation are not yet precisely determined, recent studies have pointed to this hormone as a viable marker for examining ovarian activity.

Basal AMH, which can be determined prior to stimulation (usually on day 3 of the cycle), was considered a better marker for assessing decreased ovarian reserve when compared with the classic parameters: increased follicle stimulating hormone ( $\mathrm{FSH})$, decreased inhibin $\mathrm{B}$, or antral follicle count (de Vet et al., 2002; Fanchin et al., 2003; 2005; Muttukrishna et al., 2005; Tremellen et al., 2005; Hazout, 2006). In addition, AMH is inversely correlatedwith age andbaseline FSH values; and it is directly correlated with AFC (Piltonen et al., 2005).

According to assisted reproduction technology (ART), AMH serum, AFC, and age also prove to be the most reliable hormonal marker of ovarian response to gonadotropin-controlled ovarian hyperstimulation $(\mathrm{COH})$, rather than baseline $\mathrm{FSH}$, estradiol, and inhibin B levels (Anckaert et al., 2012; Hazout et al., 2004; Muttukrishna et al., 2004; 
Nardo et al., 2009; Peñarrubia et al., 2005; Seifer et al., 2002). However, AMH, AFC and age are not a good predictor of embryo quality or pregnancy in controlled ovarian stimulation cycles. Thus, these markers are suggested to be only quantitative and not qualitative for the ovarian reserve (Broer et al., 2011; Nelson et al., 2007; Smeenk et al., 2007). Age can, nevertheless, be a good predictor of embryo quality (Scheffer et al., 2017).

Currently, we check IVF cycle success by embryo quality, where embryonic development is assessed by parameters associated with their morphological appearance, or markers, which can thus determine embryo health and quality (Puissant et al., 1987; Gardner et al., 2000).

The goal of the present prospective study was to evaluate which ovarian reserve marker would be most reliable regarding the quality of $A+B$ day 3 embryos and blastocyst; and demonstrate whether age, AFC and AMH are markers of quality and not just oocyte quantity.

\section{MATERIAL AND METHODS}

\section{Subjects}

We ran a prospective study involving 124 infertile women, aged $24-48$ years, undergoing routine exploration during an unstimulated cycle that preceded ART at our center, from May 2017 to October 2018. All patients met the following inclusion criteria: i) both ovaries present, ii) no current or past diseases affecting ovaries, gonadotropin or sex steroid secretion, clearance, or excretion, iii) no current hormone therapy, iv) adequate visualization of ovaries at transvaginal ultrasound scans, and v) total number of small antral follicles (3-12 $\mathrm{mm}$ in diameter) between 1 and 32 follicles, including both ovaries, and vi) no male infertility. All patients signed an informed consent form for this analysis.

\section{Protocol}

We gave the patients leuprolide acetate (Lupron, Abbott, France), and started the GnRH-agonist at a dose of $2,0 \mathrm{mg}$ per day during the midluteal phase, with approximately a 5-day overlap with the contraceptive (Diane 35, Schering, Brasil). We monitored their pituitary down-regulation, and patients with adequate pituitary desensitization started their recombinant FSH regime (Gonal-F; Merck-Serono Pharmaceuticals, Italy), and reduced the GnRH-agonist dose to $1,0 \mathrm{mg}$ per day. We started the $\mathrm{FSH}$ with dosages between 150 and 300 IU daily for 4 days, with or without human menopausal gonadotropin (HMG) (Menopur; Ferring Pharmaceuticals, Germany). Thereafter, we adjusted the FSH dose individually, according to the estradiol (E2) response and vaginal ultrasound findings.

When two follicles reached $\geq 16$ to $18 \mathrm{~mm}, 250 \mathrm{mg}$, we administered recombinant human Chorionic Gonadotropin (Ovidrel, Merck-Serono Pharmaceuticals, Italy) and retrieved oocytes 35 to 36 hours later.

We routinely performed intracytoplasmic sperm Injection (ICSI) in all the fertilization procedures. Fertilization was evident when we spotted two pronuclei. The embryos were cultured until the day of transfer (blastocyst) in IVF Global $\AA$ media (Life Global, Canada), supplemented with $10 \%$ synthetic serum substitute (SSS), and we graded the embryos on day 3 using the Veeck's (Veeck, 1999) criteria, and the blastocyst by Gardner's grading scale (Gardner et al., 2000).

The same embryologist performed all embryology and embryo scoring in this study. We classified the embryos on day 3 and blastocyst (day 5 ).

\section{Hormonal Measurements and UItrasound Scans}

On day 3 of the cycle, preceding $\mathrm{COH}$, we submitted the women to blood sampling by venipuncture for serum $\mathrm{AMH}$, and $\mathrm{FSH}$ measurement, and a transvaginal ovarian ultrasound scan for follicle measurement.
We determined $\mathrm{AMH}$ and $\mathrm{FSH}$ serum levels using an automated multianalysis system, with chemiluminescence detection (ACS-180; Bayer Diagnostics, Puteaux, France). Serum AMH levels were determined using a second generation enzyme-linked immunosorbent assay. Intra- and inter- assay variation coefficients (VC) were $<6$ and $<10 \%$ respectively, with lower detection limits of $0.13 \mathrm{ng} / \mathrm{ml}$ and linearity up to $21 \mathrm{ng} / \mathrm{ml}$ for $\mathrm{AMH}$. The functional sensitivity for $\mathrm{FSH}$ was $0.1 \mathrm{mIU} / \mathrm{ml}$, and intra-assay and interassay $\mathrm{CV}$ were $3 \%$ and $5 \%$, respectively.

Ultrasound scans were performed using a $3.7-9.3 \mathrm{MHz}$ multifrequency transvaginal probe (RIC5-9H; General Electric Medical Systems, Paris, France) by a single operator who was blinded as to the results of the hormone assays. The ultrasound examination aimed at evaluating the number and size of small antral follicles. Follicles measuring 3-12 $\mathrm{mm}$ in mean diameter (mean of two orthogonal diameters) in both ovaries were considered. To optimize the ovarian follicular assessment reliability, the ultrasound scanner was equipped with a tissue harmonic imaging system, which allowed improved image resolution and adequate recognition of follicular borders. Intra-analysis CV for follicular and ovarian measurements were $<5 \%$, and their lower limit of detection was $0.1 \mathrm{~mm}$. In an effort to evaluate the bulk of granulosa cells in both ovaries, we calculated the mean follicle diameter (cumulative follicle diameter divided by the number of follicles measuring 3-12 $\mathrm{mm}$ in diameter in both ovaries) and the largest follicle diameter.

\section{Groups and Subgroups}

The patients were divided into 3 groups according to age; $<35$ years ( 62 patients), $35-37$ years (31 patients) and $>37$ years ( 31 patients). After this division, the groups were compared for $\mathrm{AMH}, \mathrm{AFC}$ and number of $\mathrm{A}+\mathrm{B}$ embryos (day 3 and blastocyst). Thereafter, we divided the 3 groups again, based on the $\mathrm{AMH} ;<1 \mathrm{ng} / \mathrm{ml}$ (32 patients); $1-2 \mathrm{ng} /$ $\mathrm{ml}$ ( 32 patients); $>2 \mathrm{ng} / \mathrm{ml}$ ( 60 patients) and we compared the groups for age, AFC and number of $A+B$ embryos (day 3 and blastocyst).

Finally the patients were again divided into 3 groups based on the AFC; $>7$ (30 patients); 8-14 (34 patients); $>14$ (60 patients) and the groups were compared for age, $\mathrm{AMH}$, number of $\mathrm{A}+\mathrm{B}$ embryos (day 3 and blastocyst). The criteria used in the group divisions and subgroups regarding age, $A M H$ and AFC were based on the scientific literature (Bishop et al., 2017; Kim, 2017).

These divisions in groups based on the main ovarian reserve markers aimed at evaluating which marker would be more reliable as the quality of the $A+B$ embryos (day 3 and blastocyst).

\section{Statistical Analysis}

Descriptive parameters and patient characteristics were reported as mean SD or median (range), depending on the distribution. The Student's t-test was performed for continuous variables; Wilcoxon and Pearson's Test were used where appropriate for categorical variables. $p<.05$ was considered statistically significant.

\section{Ethical approval and consent to participate}

Written informed consent was obtained from all participants before inclusion. The study was approved by the IBRRA Ethical Committee. Our patients signed an informed consent form for this analysis. Because the present study was merely observational and included only data from routine measurements, it did not require previous submission to our institutional review board.

\section{RESULTS}

Overall, at the time of this investigation, patients had a mean age of $34.28 \pm 4.02$ years old; BMI of $24.92 \pm 3.14 \mathrm{~kg} /$ 
$\mathrm{m}^{2}$; and length of infertility of $3.44 \pm 2.44$ years. On cycle day 3 , the serum AMH level was $2.69 \pm 2.52 \mathrm{ng} / \mathrm{ml}$ and the serum FSH level was $12.68 \pm 9.26 \mathrm{mUI} / \mathrm{ml}$. At baseline, women had $12.53 \pm 5.34$ antral follicles. Tables 1,2 and 3 demonstrate the characteristics of each subgroup.

When the 124 patients were divided according to age, there was a significant fall in AMH and AFC among those older than 35 years $(p<0.006 ; p<0.003)$, and it was more severe after 37 years of age $(p<0.003 ; p<0.002)$. And the fall in $A+B$ embryo quality (day 3 ; blastocyst, respectively) was significant after 35 years $(p<0.038 ; p<0.035)$ and even more severe after 37 years $(p<0.032 ; p<0.027)$.

When the 124 patients were divided according to $\mathrm{AMH}$, there was a significantly negative correlation with age $(p<0.05)$, and this was more intense with $\mathrm{AMH}<1 \mathrm{ng} /$ $\mathrm{ml}(p<0.001)$; as well as a significantly positive relationship with AFC $(p<0.05)$ and more intense with AMH $>2 \mathrm{ng} /$ $\mathrm{ml}(p<0.001)$. And the fall in A+B embryo quality (day 3 ; blastocyst, respectively) was significant with $A M H<1 \mathrm{ng} / \mathrm{ml}$ $(p<0.023 ; p<0.021)$.

When the 124 patients were divided according to AFC, there was a significantly negative correlation with age $(p<0.05)$, and this was more intense with AFC $<7 \mathrm{ng} / \mathrm{ml}$ $(p<0.001)$; as well as a significantly positive relationship with AMH $(p<0.05)$, and even more intense with AFC $>14$ $(p<0.006)$. And the fall in A+B embryo quality (day 3 ; blastocyst, respectively) was significant with AFC $<7$ ( $p<0.025$; $p<0.023)$.

Table 4 shows that markers, age, AFC and $\mathrm{AMH}$ had significant associations with $A+B$ embryo quality on day 3 and that the strength of significance was higher with $\mathrm{AMH}$ $(p=0.307 ; p<0.006)$ and AFC $(p=0.310 ; p<0.005)$ than age $(p=-0.137 ; p<0,023)$.

However, Table 5 shows that the strength of significance was equal between AMH $(p=0.290 ; p<0.005)$, AFC $(\mathrm{p}=0.295 ; p<0.005)$, and age $(p=-0.28 ; p<0.005)$ with blastocyst quality.

\section{DISCUSSION}

This study validated the association between clinical measures often used in ovarian reserve and embryo quality on the third day and in the blastocyst stage. There was an association between basal $\mathrm{AMH}$, age and AFC with embryo quality. Thus, they may contribute as a possible explanation to the results of some studies that show the associations of markers with the probability of pregnancy, since embryo quality is fundamental for clinical success. There are suggestions that these markers are quantitative and qualitative vis-à-vis the ovarian reserve. Although ovarian reserve markers demonstrate clinical importance in assisted reproduction treatments, they may indicate not only clinical but embryo prognosis as well.

Our group demonstrated that female age is a predictive marker of the number of oocytes collected, number of oocytes in MII and embryo quality (Scheffer et al., 2017). This relationship between age and embryo quality is due to the oocyte quality that will then influence embryo quality. Women transfer half of the chromosomal complement to the embryo, although the maternal and paternal genomes are not symmetrical and equal in their influence on the embryo. Oocytes unfortunately show a drop in quality with age, due to genetic changes. The incidence of non-disjunction and early chromatid separation correlated to maternal aging. Disturbance in sister chromatid cohesion might be a causal mechanism predisposing to premature chromatid separation and subsequently to nondisjunction in female meiosis. In addition, the asymmetry of female meiosis division could favor a nonrandom meiotic segregation of chromosomes and chromatids.

\begin{tabular}{|c|c|c|c|c|c|c|}
\hline Age Subgroups & BMI & AMHd3 & AFCd3 & FSH d3 & \multicolumn{2}{|c|}{ Total FSH dose } \\
\hline$<35$ years & $24.26 \pm .91$ & $3.34 \pm 2.31$ & $14.78 \pm 4.55$ & $9.36 \pm 4.10$ & \multicolumn{2}{|c|}{$1,539 \pm 443.15$} \\
\hline$\geq 35-\leq 37$ years & $25.59 \pm 3.36$ & $2.28 \pm 3.19$ & $10.29 \pm 5.43$ & $16.26 \pm 10.80$ & \multicolumn{2}{|c|}{$2,190 \pm 788.21$} \\
\hline$>37$ years & $25.62 \pm 3.24$ & $1.71 \pm 1.70$ & $10.17 \pm 4.95$ & $15.89 \pm 12.84$ & \multicolumn{2}{|c|}{$2,025 \pm 426.33$} \\
\hline Age Subgroups & $\begin{array}{c}\text { Stimulation } \\
\text { duration }\end{array}$ & Foll total & MII & Total Embryos & $\begin{array}{c}A+B \\
\text { Embryos } \\
\text { (day3) }\end{array}$ & $\begin{array}{c}A+B \\
\text { Embryos } \\
\text { (Blastocyst) }\end{array}$ \\
\hline$<35$ years & $10.28 \pm 2.00$ & $13.10 \pm 5.37$ & $7.68 \pm 3.92$ & $5.23 \pm 2.94$ & $2.58 \pm 2.05$ & $2.10 \pm 0.95$ \\
\hline$\geq 35-\leq 37$ years & $10.33 \pm 1.49$ & $10.00 \pm 4.56$ & $7.29 \pm 4.43$ & $5.29 \pm 3.48$ & $3.29 \pm 2.74$ & $2.09 \pm 0.88$ \\
\hline$>37$ years & $10.50 \pm 1.62$ & $8.72 \pm 5.07$ & $4.56 \pm 3.24$ & $3.22 \pm 2.60$ & $1.39 \pm 1.65$ & $1.20 \pm 0.70$ \\
\hline
\end{tabular}

\begin{tabular}{|l|c|c|c|c|c|c|}
\hline \multicolumn{1}{|l|}{ Table 2. Characteristics of AMH subgroups $(\mathrm{ng} / \mathrm{ml})$} \\
\hline AMH Subgroups & BMI & Age & AFCd3 & FSH d3 & \multicolumn{2}{|c|}{ Total dose of FSH } \\
\hline $0-1 \mathrm{ng} / \mathrm{ml}$ & $25.91 \pm 2.83$ & $36.77 \pm 3.29$ & $6.50 \pm 2.54$ & $23.23 \pm 11.79$ & \multicolumn{2}{|c|}{$2.600 \pm 510.03$} \\
\hline $1.1-2 \mathrm{ng} / \mathrm{ml}$ & $23.88 \pm 2.59$ & $33.83 \pm 3.94$ & $10.72 \pm 2.05$ & $11.28 \pm 2.05$ & \multicolumn{2}{|c|}{$1.675 \pm 297.61$} \\
\hline$>2 \mathrm{ng} / \mathrm{ml}$ & $24.84 \pm 3.43$ & $33.08 \pm 3.88$ & $16.77 \pm 3.47$ & $7.39 \pm 1.77$ & \multicolumn{2}{|c|}{$1.453 \pm 323.02$} \\
\hline AMH Subgroups & $\begin{array}{c}\text { Stimulation } \\
\text { duration }\end{array}$ & Foll total & MII & $\begin{array}{c}\text { Total } \\
\text { Embryos }\end{array}$ & $\begin{array}{c}\text { A+B B } \\
\text { Embryos }\end{array}$ \\
\hline $0-1 \mathrm{ng} / \mathrm{ml}$ & $10.27 \pm 1.35$ & $5.96 \pm 3.05$ & $4.59 \pm 2.59$ & $3.23 \pm 1.9$ & $1.64 \pm 1.62$ & $1.02 \pm 0.83$ \\
\hline $1.1-2 \mathrm{ng} / \mathrm{ml}$ & $10.11 \pm 1.41$ & $10.39 \pm 4.16$ & $6.44 \pm 4.15$ & $4.50 \pm 3.45$ & $2.06 \pm 1.86$ & $1.98 \pm 0.99$ \\
\hline$>2 \mathrm{ng} / \mathrm{ml}$ & $10.49 \pm 2.13$ & $14.54 \pm 4.41$ & $8.33 \pm 4.18$ & $5.80 \pm 3.16$ & $3.18 \pm 2.53$ & $2.07 \pm 1.00$ \\
\hline
\end{tabular}




\begin{tabular}{|l|c|c|c|c|c|c|}
\hline \multicolumn{2}{|l|}{ Table 3. Characteristics of AFC subgroups $(\mathrm{n})$} \\
\hline AFC Subgroups & BMI & Age & AMH & FSH d3 & \multicolumn{2}{|c|}{ Total dose of Medicines } \\
\hline $0-7$ & $25.00 \pm 2.50$ & $36.93 \pm 3.53$ & $0.61 \pm 0.37$ & $25.87 \pm 13.42$ & \multicolumn{2}{|c|}{$2.671 \pm 419.08$} \\
\hline $8-14$ & $24.72 \pm 3.08$ & $34.24 \pm 4.09$ & $1.74 \pm 0.75$ & $11.31 \pm 4.17$ & \multicolumn{2}{|c|}{$1.803 \pm 508.34$} \\
\hline$>14$ & $25.15 \pm 3.60$ & $32.85 \pm 3.53$ & $5.14 \pm 2.87$ & $7.25 \pm 1.61$ & \multicolumn{2}{|c|}{$1.380 \pm 284.30$} \\
\hline AFC Subgroups & $\begin{array}{c}\text { Stimulation } \\
\text { duration }\end{array}$ & Foll total & MII & Total Embryos & $\begin{array}{c}\text { A+B Embryos } \\
\text { Embryos } \\
\text { (Blastocyst) }\end{array}$ \\
\hline $0-7$ & $10.20 \pm 1.47$ & $5.20 \pm 3.53$ & $4.73 \pm 2.89$ & $3.33 \pm 2.19$ & $1.60 \pm 1.80$ & $1.93 \pm 0.56$ \\
\hline $8-14$ & $10.19 \pm 1.33$ & $10.49 \pm 3.88$ & $6.46 \pm 3.81$ & $4.57 \pm 3.02$ & $2.32 \pm 1.92$ & $2.10 \pm 0.76$ \\
\hline$>14$ & $10.63 \pm 2.39$ & $15.52 \pm 4.39$ & $8.59 \pm 4.40$ & $5.89 \pm 3.33$ & $3.22 \pm 2.71$ & $2.70 \pm 1.80$ \\
\hline
\end{tabular}

Table 4. Associations between age, AMH and AFC with day 3 Embryo-Quality (Pearson's Test)

\begin{tabular}{|l|c|c|}
\hline & $\boldsymbol{p}$ & $\boldsymbol{p}$-value \\
\hline Age $\times$ Embryos A+B & -0.137 & 0.023 \\
\hline AMH $\times$ Embryos A+B & 0.307 & 0.006 \\
\hline AFC $\times$ Embryos A+B & 0.310 & 0.005 \\
\hline
\end{tabular}

Table 5. Relationship between markers age, AMH and AFC with Embryos Blastocyst Quality (Pearson's Test)

\begin{tabular}{|l|c|c|}
\hline & $\boldsymbol{p}$ & $\boldsymbol{p}$-value \\
\hline Age $\times$ Embryos A+B & -0.280 & 0.005 \\
\hline AMH $\times$ Embryos A+B & 0.290 & 0.005 \\
\hline AFC $\times$ Embryos A+B & 0.295 & 0.005 \\
\hline
\end{tabular}

In some studies, there was an age-association with the expression of certain genes and proteins involved in mitochondrial function. Mitochondria play a role in cellular energy metabolism, homeostasis and cell death, and are directly involved in oogenesis and folliculogenesis. With age, there is an increase in damage to mitochondrial DNA. Mitochondrial mutations in follicular cells are observed in oocytes of older women, causing a decrease in the quality of these oocytes (McReynolds et al., 2012).

Age correlates with embryo quality and also with $\mathrm{AMH}$ and AFC. This paper reports that these two ovarian reserve markers may also be associated with embryo quality. We assessed the correlation of these markers with embryo quality on day 3, where the main genetic expression is maternal, while in the blastocyst stage it is more embryonic, that is; it has both paternal and maternal performance. This assessment is important because these markers reflect the most advanced embryonic development, of which maternal and paternal gene expression is most significant. Although there was no case of male infertility, it is practical to perform ICSI in all cases.

Oxidative stress may affect embryo quality (Agarwal et al., 2005), although even morphologically normal embryos may have an abnormal number of chromosomes and low pregnancy rates. However, the possibility that the main factor in the etiology of female infertility is associated with age is that the decline in oocyte quality is associated with factors such as chromosomal aneuploidy and mitochondrial dysfunction (Twisk et al., 2006; Cheng et al., 2009; Eichenlaub-Ritter et al., 2011). However, the underlying mechanisms are still inconclusive.
The objective of the study was to assess embryo quality, so no pregnancy rate was analyzed. This is yet to be evaluated by the authors. It is important to highlight some limitations present in the study, such as the small sample size, which may limit the ability to demonstrate the additional value of these markers with embryo quality. In addition, there are many published embryo scoring systems (Desai et al., 2000; Steer et al., 1992; Hoover et al., 1995; Rienzi et al., 2002; Fisch et al., 2001). Despite the systematic approach of such scoring systems to compare and contrast embryos, embryo morphology and assigning of a grade is, by default and design, a subjective process subject to interobserver and intraobserver variability although in our case all embryos were evaluated by the same embryologist.

Initially the pregnancy rate, ongoing pregnancy rate or live birth rates were not the primary objective of this study. But the authors are finishing other studies that will be added to these rates as a primary objective, thus bringing new knowledge about these markers in the future. Despite possible biases, this study is important in that it demonstrates that these markers can reflect both the quantity and quality of the ovarian reserve, and encourage further studies on this topic. Moreover, due to the limitations of physicians in their countries, especially in poor or developing countries, in evaluating all three markers, this study also ensures that the evaluation of at least one marker has already enabled physicians to have better embryonic prognoses.

Embryo quality assessment can also be performed using invasive methods, such as PGT-A, and non-invasive methods such as Time Lapse. However, both methodologies have flaws due to their subjectivities, damage to the embryo and questionable results. Because some centers are unable to use these methodologies, other evaluation methods should also be analyzed according to the objective of this study.

Therefore, more studies can improve the accuracy and interpretation of current ovarian reserve markers relating to embryonic quality and clinical pregnancy rates.

\section{CONCLUSION}

In summary, we demonstrated that commonly used clinical markers of ovarian reserve are reflective of the true ovarian reserve, and AMH, AFC and age are markers of embryo quality; therefore, they are markers of ovarian reserve quantity and quality.

\section{Acknowledgement section}

The authors wish to thank the Brazilian Institute of Assisted Reproduction for financially supporting our study. 


\section{CONFLICT OF INTEREST}

The authors declare that there are no conflicts of interest.

\section{Corresponding author:}

Juliano Augusto Brum Scheffer

IBRRA - Brazilian Institute of Assisted Reproduction

Belo Horizonte - Minas Gerais - BRAZIL.

E-mail: drjulianoscheffer@gmail.com

ORCID: 0000-0002-7070-9643

\section{REFERENCES}

Agarwal A, Gupta S, Sharma R. Oxidative stress and its implications in female infertility - a clinician's perspective. Reprod Biomed Online. 2005;11:641-50. PMID: 16409717 DOI: $10.1016 / S 1472-6483(10) 61174-1$

Anckaert E, Smitz J, Schiettecatte J, Klein B, Arce JC. The value of anti-Mullerian hormone measurement in the long GnRH agonist protocol: association with ovarian response and gonadotrophin-dose adjustments. Hum Reprod. 2012;27:1829-39. PMID: 22473395 DOI: 10.1093/humrep/des 101

Bishop LA, Richter KS, Patounakis G, Andriani L, Moon $\mathrm{Km}$ Devine $\mathrm{K}$. Diminished ovarian reserve as measured by means of baseline follicle-stimulating hormone and antral follicle count is not associated with pregnancy loss in younger in vitro fertilization patients. Fertil Steril. 2017;108:980-7. PMID: 29202975 DOI: 10.1016/j.fertnstert.2017.09.011

Broer SL, Dólleman M, Opmeer BC, Fauser BC, Mol BW, Broekmans FJ. AMH and AFC as predictors of excessive response in controlled ovarian hyperstimulation: a meta-analysis. Hum Reprod Update. 2011;17:46-54. PMID: 20667894 DOI: 10.1093/humupd/dmq034

CDC - Centers for Disease Control and Prevention, American Society for Reproductive Medicine, Society for Assisted Reproductive Technology. 2001 Assisted Reproductive Technology Success Rates. Atlanta: US Department of Health and Human Services, CDC; 2003.

Cheng EY, Hunt PA, Naluai-Cecchini TA, Fligner CL, Fujimoto VY, Pasternack TL, Schwartz JM, Steinauer JE, Woodruff TJ, Cherry SM, Hansen TA, Vallente RU, Broman KW, Hassold TJ. Meiotic recombination in human oocytes. PLoS Genet. 2009;5:e1000661. PMID: 19763179 DOI: 10.1371/ journal.pgen.1000661

de Vet A, Laven JS, de Jong FH, Themmen AP, Fauser BC. Antimüllerian hormone serum levels: a putative marker for ovarian aging. Fertil Steril. 2002;77:357-62. PMID: 11821097 DOI: $10.1016 /$ S0015-0282(01)02993-4

Desai NN, Goldstein J, Rowland DY, Goldfarb JM. Morphological evaluation of human embryos and derivation of an embryo quality scoring system specific for day 3 embryos: a preliminary study. Hum Reprod. 2000;15:2190-6. PMID: 11006197 DOI: $10.1093 /$ humrep/15.10.2190

di Clemente N, Ghaffari S, Pepinsky RB, Pieau C, Josso $\mathrm{N}$, Cate RL, Vigier B. A quantitative and interspecific test for biological activity of anti-müllerian hormone: the fetal ovary aromatase assay. Development. 1992;114:721-7. PMID: 1319894
Durlinger $A L$, Gruijters $M J$, Kramer $P$, Karels $B$, Ingraham HA, Nachtigal MW, Uilenbroek JT, Grootegoed JA, Themmen AP. Anti-Müllerian hormone inhibits initiation of primordial follicle growth in the mouse ovary. Endocrinology. 2002;143:1076-84. PMID: 11861535 DOI: 10.1210/ endo.143.3.8691

Eichenlaub-Ritter U, Wieczorek M, Luke S, Seidel T. Age related changes in mitochondrial function and new approaches to study redox regulation in mammalian oocytes in response to age or maturation conditions. Mitochondrion. 2011;11:78396. PMID: 20817047 DOI: 10.1016/j.mito.2010.08.011

Fanchin R, Schonäuer LM, Righini C, Guibourdenche J, Frydman R, Taieb J. Serum anti-Müllerian hormone is more strongly related to ovarian follicular status than serum inhibin $B$, estradiol, FSH and LH on day 3. Hum Reprod. 2003;18:323-7. PMID: 12571168 DOI: 10.1093/humrep/deg042

Fanchin R, Taieb J, Lozano DH, Ducot B, Frydman R, Bouyer J. High reproducibility of serum anti-Mullerian hormone measurements suggests a multi-staged follicular secretion and strengthens its role in the assessment of ovarian follicular status. Hum Reprod. 2005;20:923-7. PMID: 15640257 DOI: $10.1093 /$ humrep/deh688

Fisch JD, Rodriguez H, Ross R, Overby G, Sher G. The Graduated Embryo Score (GES) predicts blastocyst formation and pregnancy rate from cleavage-stage embryos. Hum Reprod. 2001;16:1970-5. PMID: 11527907 DOI: 10.1093/humrep/16.9.1970

Gardner DK, Lane M, Stevens J, Schlenker T, Schoolcraft WB. Blastocyst score affects implantation and pregnancy outcome: towards a single blastocyst transfer. Fertil Steril. 2000;73:1155-8. PMID: 10856474 DOI: 10.1016/S00150282(00)00518-5

Guibourdenche J, Lucidarme N, Chevenne D, Rigal O, Nicolas $M$, Luton $D$, Léger J, Porquet $D$, Noël M. Anti-Müllerian hormone levels in serum from human foetuses and children: pattern and clinical interest. Mol Cell Endocrinol. 2003;211:55-63. PMID: 14656477 DOI: $10.1016 / j$. mce.2003.09.011

Hazout A, Bouchard P, Seifer DB, Aussage P, Junca AM, Cohen-Bacrie P. Serum antimullerian hormone/mullerian-inhibiting substance appears to be a more discriminatory marker of assisted reproductive technology outcome than follicle-stimulating hormone, inhibin B, or estradiol. Fertil Steril. 2004;82:1323-9. PMID: 15533354 DOI: $10.1016 / j$. fertnstert.2004.03.061

Hazout A. Quality of ovarian reserve: inhibin B on day 3 of the cycle or antimüllerian hormone $(\mathrm{AMH})$ ? Gynecol Obstet Fertil. 2006;34:1001-2. PMID: 17070720 DOI: $10.1016 / j$. gyobfe.2006.09.012

Hoover L, Baker A, Check JH, Lurie D, O'Shaughnessy A. Evaluation of a new embryo-grading system to predict pregnancy rates following in vitro fertilization. Gynecol Obstet Invest. 1995;40:151-7. PMID: 8529946 DOI: $10.1159 / 000292326$

Kim HH. Markers of ovarian reserve: is it possible to estimate an ovarian age? Fertil Steril. 2017;108:950-1. PMID: 29202969 DOI: $10.1016 /$ j.fertnstert.2017.10.023 
La Marca A, De Leo V, Giulini S, Orvieto R, Malmusi S, Giannella L, Volpe A. Anti-Mullerian hormone in premenopausal women and after spontaneous or surgically induced menopause. J Soc Gynecol Investig. 2005;12:545-8. PMID: 16046154 DOI: 10.1016/j.jsgi.2005.06.001

McReynolds S, Dzieciatkowska M, McCallie BR, Mitchell SD, Stevens J, Hansen K, Schoolcraft WB, Katz-Jaffe MG. Impact of maternal aging on the molecular signature of human cumulus cells. Fertil Steril. 2012;98:1574-80.e5. PMID: 22968048 DOI: 10.1016/j.fertnstert.2012.08.012

Muttukrishna S, Suharjono H, McGarrigle H, Sathanandan $M$. Inhibin $B$ and anti-Mullerian hormone: markers of ovarian response in IVF/ICSI patients? BJOG. 2004;111:1248-53. PMID: 15521870 DOI: $10.1111 / j .1471-0528.2004 .00452 . x$

Muttukrishna S, McGarrigle H, Wakim R, Khadum I, Ranieri DM, Serhal P. Antral follicle count, anti-mullerian hormone and inhibin $\mathrm{B}$ : predictors of ovarian response in assisted reproductive technology? BJOG. 2005;112:1384-90. PMID: 16167941 DOI: $10.1111 /$ j.1471-0528.2005.00670.x

Nardo LG, Gelbaya TA, Wilkinson $H$, Roberts SA, Yates A, Pemberton P, Laing I. Circulating basal anti-Müllerian hormone levels as predictor of ovarian response in women undergoing ovarian stimulation for in vitro fertilization. Fertil Steril. 2009;92:1586-93. PMID: 18930213 DOI: 10.1016/j.fertnstert.2008.08.127

Nelson SM, Yates RW, Fleming R. Serum anti-Müllerian hormone and FSH: prediction of live birth and extremes of response in stimulated cycles--implications for individualization of therapy. Hum Reprod. 2007;22:2414-21. PMID: 17636277 DOI: $10.1093 /$ humrep/dem204

Peñarrubia J, Fábregues F, Manau D, Creus M, Casals G, Casamitjana R, Carmona F, Vanrell JA, Balasch J. Basal and stimulation day 5 anti-Mullerian hormone serum concentrations as predictors of ovarian response and pregnancy in assisted reproductive technology cycles stimulated with gonadotropin-releasing hormone agonist--gonadotropin treatment. Hum Reprod. 2005;20:915-22. PMID: 15665015 DOI: $10.1093 /$ humrep/deh718

Piltonen T, Morin-Papunen L, Koivunen R, Perheentupa A, Ruokonen A, Tapanainen JS. Serum anti-Müllerian hormone levels remain high until late reproductive age and decrease during metformin therapy in women with polycystic ovary syndrome. Hum Reprod. 2005;20:1820-6. PMID: 15802325 DOI: 10.1093/humrep/deh850

Puissant F, Van Rysselberge M, Barlow P, Deweze J, Leroy $F$. Embryo scoring as a prognostic tool in IVF treatment. Hum Reprod. 1987;2:705-8. PMID: 3437050 DOI: 10.1093/oxfordjournals.humrep.a136618

Rajpert-De Meyts E, Jørgensen N, Graem N, Müller J, Cate $\mathrm{RL}$, Skakkebaek NE. Expression of anti-Müllerian hormone during normal and pathological gonadal development: association with differentiation of Sertoli and granulosa cells. J Clin Endocrinol Metab. 1999;84:3836-44. PMID: 10523039 DOI: $10.1210 /$ jcem.84.10.6047
Rienzi L, Ubaldi F, Iacobelli M, Ferrero S, Minasi MG, Martinez F, Tesarik J, Greco E. Day 3 embryo transfer with combined evaluation at the pronuclear and cleavage stages compares favourably with day 5 blastocyst transfer. Hum Reprod. 2002;17:1852-5. PMID: 12093851 DOI: 10.1093/ humrep/17.7.1852

Scheffer JB, Scheffer BB, de Carvalho RF, Rodrigues J, Grynberg M, Mendez Lozano DH. Age as a Predictor of Embryo Quality Regardless of the Quantitative Ovarian Response. Int J Fertil Steril. 2017;11:40-6. PMID: 28367304 DOI: $10.22074 /$ ijfs. 2016.4579

Seifer DB, MacLaughlin DT, Christian BP, Feng B, Shelden RM. Early follicular serum müllerian-inhibiting substance levels are associated with ovarian response during assisted reproductive technology cycles. Fertil Steril. 2002;77:468-71. PMID: 11872196 DOI: $10.1016 /$ S00150282(01)03201-0

Smeenk JM, Sweep FC, Zielhuis GA, Kremer JA, Thomas $\mathrm{CM}$, Braat DD. Antimüllerian hormone predicts ovarian responsiveness, but not embryo quality or pregnancy, after in vitro fertilization or intracyoplasmic sperm injection. Fertil Steril. 2007;87:223-6. PMID: 17081531 DOI: 10.1016/j. fertnstert.2006.06.019

Steer CV, Mills CL, Tan SL, Campbell S, Edwards RG. The cumulative embryo score: a predictive embryo scoring technique to select the optimal number of embryos to transfer in an in-vitro fertilization and embryo transfer programme. Hum Reprod. 1992;7:117-9. PMID: 1551945 DOI: $10.1093 /$ oxfordjournals.humrep.a137542

Tremellen KP, Kolo M, Gilmore A, Lekamge DN. Anti-mullerian hormone as a marker of ovarian reserve. Aust N Z J Obstet Gynaecol. 2005;45:20-4. PMID: 15730360 DOI: 10.1111/j.1479-828X.2005.00332.x

Twisk M, Mastenbroek S, van Wely M, Heineman MJ, Van der Veen $F$, Repping S. Preimplantation genetic screening for abnormal number of chromosomes (aneuploidies) in in vitro fertilisation or intracytoplasmic sperm injection. Cochrane Database Syst Rev. 2006;25:CD005291. PMID: 16437524 DOI: 10.1002/14651858.CD005291.pub2

Weenen C, Laven JS, Von Bergh AR, Cranfield M, Groome NP, Visser JA, Kramer P, Fauser BC, Themmen AP. Anti-Müllerian hormone expression pattern in the human ovary: potential implications for initial and cyclic follicle recruitment. Mol Hum Reprod. 2004;10:77-83. PMID: 14742691 DOI: $10.1093 / \mathrm{molehr} / \mathrm{gah} 015$

Veeck LL. Atlas of human gametes and conceptuses. New York: Parthenon Publishing; 1999.

Vigier B, Picard JY, Tran D, Legeai L, Josso N. Production of anti-Müllerian hormone: another homology between Sertoli and granulosa cells. Endocrinology. 1984;114:131520. PMID: 6546716 DOI: $10.1210 /$ endo-114-4-1315 